\title{
Efficacy and safety of Tripterygium wilfordii hook F for chronic urticaria: a systematic review and meta-analysis
}

Liu Liu ${ }^{1 \dagger}$, Huaibo Zhao ${ }^{1 \dagger}$, Xiaoying Sun ${ }^{2}$, Qi Zheng ${ }^{1}$, Ying Luo ${ }^{1}, Y_{i}$ Ru$^{1}$, Ying Zhang ${ }^{1}$, Xi Chen ${ }^{1}$, Bo Zhu ${ }^{4}$, Chengqian $\mathrm{Yin}^{4}$, Bin $\mathrm{Li}^{1,2,3^{*}}$ and Xin $\mathrm{Li}^{1,2^{*}}$ (D)

\begin{abstract}
Background: The first-line agents comprising antihistamines for chronic urticaria, are not completely satisfactory. Tripterygium wilfordii Hook F (TwHF), a Chinese herb, has been developed into several Tripterygium agents and have definite effects on autoimmune and inflammatory diseases. In chronic urticaria, however, their values of practical application remain unclear. The aim of this study was to investigate the efficacy and safety of TwHF in patients with chronic urticaria.

Methods: Several databases were systematically searched including PubMed, Embase, Cochrane Central Register of Controlled Trials, China Network Knowledge Infrastructure, Chinese Scientific Journals Database, Wan Fang Database, and Chinese Biomedicine. Randomized controlled trials comparing antihistamines with TwHF or Tripterygium agents in combination with antihistamines were included. Revman5.3 was utilized to calculate risk ratios (RR) with 95\% confidence intervals (CI). This study was registered with PROSPERO, number CRD42018091595.

Results: Twenty-one trials with 2565 participants were included in this analysis. Meta-analysis showed that, when antihistamines were combined with TwHF and Tripterygium agents, the curative effect in cases of chronic urticaria was superior to that of antihistamines alone (RR: 1.40; 95\% Cl: 1.33-1.46). The incidence rates of gastrointestinal disorder (RR: 2.91; 95\% Cl: 1.70-4.99) and menstrual disorder (RR: 6.00; 95\% Cl: 1.79-20.13) in drug combination groups were higher than those in controls, while other adverse events were similar between the two groups. After treatment, Dermatology Life Quality Index (RR: 1.23; 95\% Cl: 1.09-1.40), quality of sleep (RR: 1.50; 95\% Cl: 1.07-2.12), and daily activity (RR: 1.49; $95 \% \mathrm{Cl}: 1.25-1.78$ ) were all improved. Furthermore, drug combination groups demonstrated less relapse (RR: 0.34; 95\% Cl: 0.25-0.45).

Conclusions: TwHF and Tripterygium agents, in combination with antihistamines, appear to be more effective than antihistamines alone. Nevertheless, adverse events cannot be ignored. Large sample, multi-center, high-quality clinical studies are needed to verify the exact effects and safety of TwHF and Tripterygium agents in treatment of chronic urticaria.
\end{abstract}

Keywords: Chronic urticaria, Tripterygium wilfordii hook F, Tripterygium agents, Systematic review, Meta-analysis

\footnotetext{
* Correspondence: 18930568129@163.com; 13661956326@163.com

†Liu Liu and Huaibo Zhao contributed equally to this work.

${ }^{1}$ Department of Dermatology, Yueyang Hospital of Integrated Traditional

Chinese and Western Medicine, Shanghai University of Traditional Chinese

Medicine, Shanghai 200437, China

Full list of author information is available at the end of the article
}

(c) The Author(s). 2018 Open Access This article is distributed under the terms of the Creative Commons Attribution 4.0 International License (http://creativecommons.org/licenses/by/4.0/), which permits unrestricted use, distribution, and reproduction in any medium, provided you give appropriate credit to the original author(s) and the source, provide a link to the Creative Commons license, and indicate if changes were made. The Creative Commons Public Domain Dedication waiver (http://creativecommons.org/publicdomain/zero/1.0/) applies to the data made available in this article, unless otherwise stated. 


\section{Background}

Urticaria is a recurrent dermatosis, characterized by spontaneous wheals, angioedema, or both. Generally, chronic urticaria is defined as occurrence of urticaria for longer than 6 weeks [1]. It affects $0.5-1 \%$ of individuals and reduces the quality of life significantly [2]. Histamine release, driven by mast cells, is regarded as the primary feature in chronic urticaria, resulting in the presence of wheals and flare [3]. Thus, treatment with antihistamines plays a crucial role in chronic urticaria. First-line agents in the routine management of chronic urticaria comprise second-generation antihistamines, such as mizolastine, levocetirizine, and desloratadine [1]. However, high recurrence rate and drug resistance are an ongoing matter of concern. Thus, better therapy is required.

Tripterygium wilfordii Hook F (TwHF) is a vital Chinese herbs belonging to the Celastraceae family. In China, four species of the genus Tripterygium are prevalent, including Tripterygium wilfordii Hook F, Tripterygium hypoglaucum (levl.) Hutch (THH), Tripterygium regelii Sprague and Takeda and Tripterygium forrestii Loes. Molecular analyses have indicated Tripterygium wilfordii and Tripterygium hypoglaucum are not distinct, while Tripterygium regelii is considered as a separate species [4]. Their effects include anti-inflammation, antianaphylaxis, and immunosuppression. In 2007, triptolide and celastrol, the main components of TwHF, along with artemisinin, capsaicin, and curcumin, were listed as the most promising natural traditional medicines [5]. Over the past few decades, several kinds of Tripterygium agents extracted from the root bark of this herb, such as Glucosidorum Tripterygll Totorum tablets (GTT), tripterygium glycosides tablets (TG), and Tripterygium hypoglaucum (levl.) Hutch tablets (THH), have been developed and used for treating autoimmune and inflammatory diseases in China; these diseases include rheumatoid arthritis [6], diabetic nephropathy [7], purpura nephritis [8], and urticaria $[9,10]$. Currently, increasing evidence has reported that TwHF combined

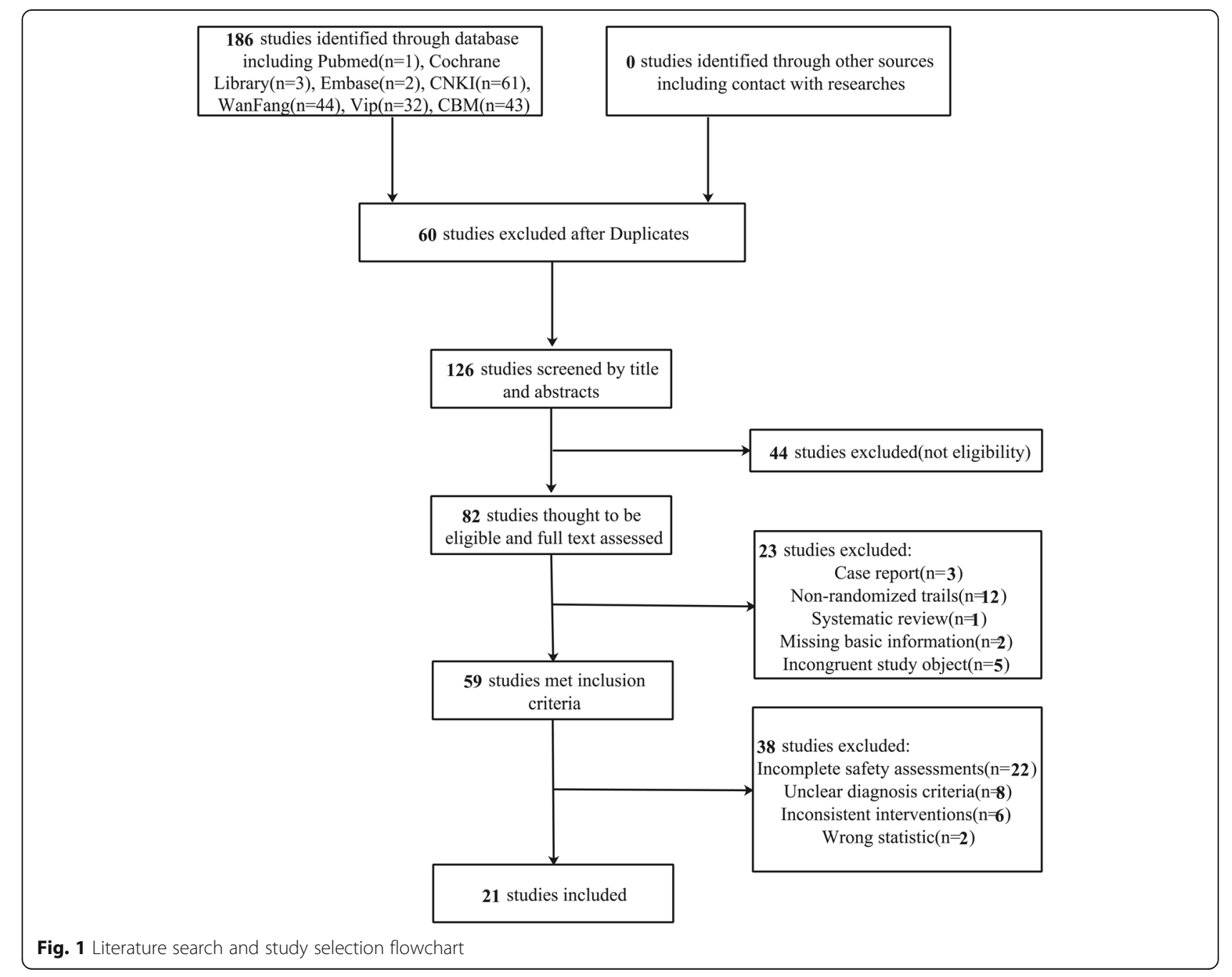




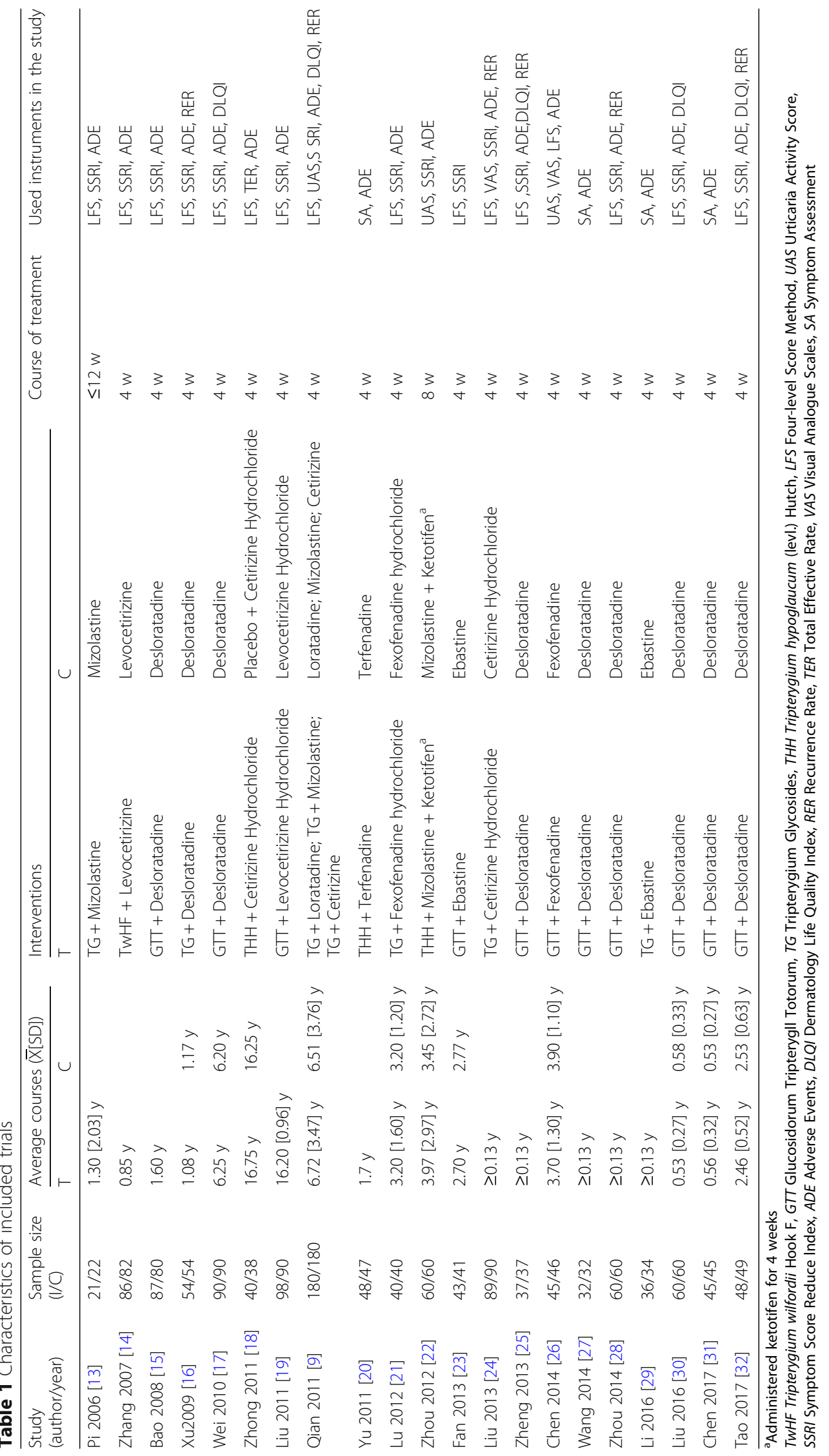




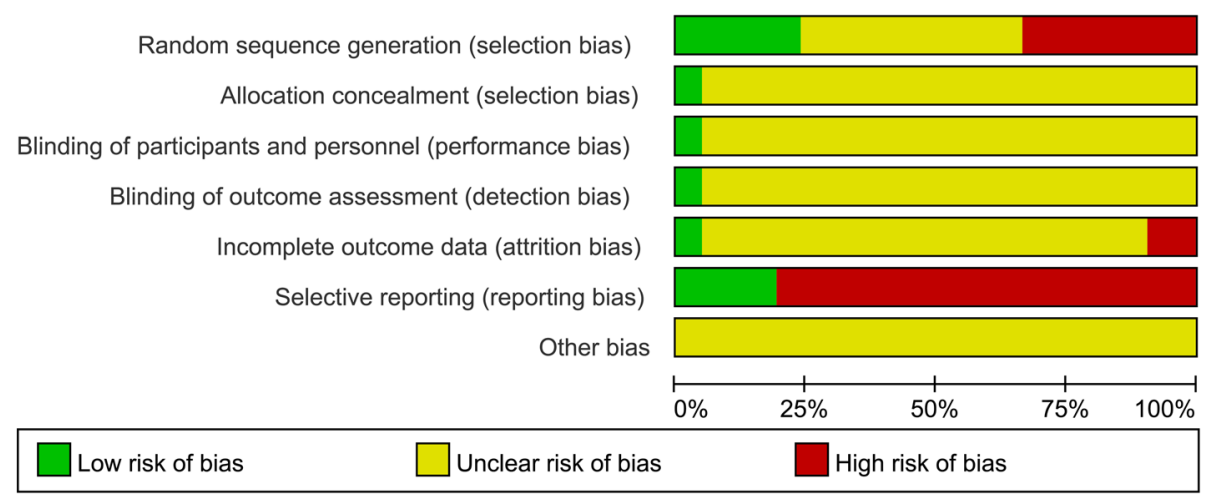

Fig. 2 Risk of bias graph

with antihistamine for chronic urticaria sufferers is satisfactory. Nevertheless, the curative effect and safety of these agents in urticaria is not clear. It is essential to evaluate the trials in this subject in order to effectively conduct the practice of medicine. Hence, we undertook this systematic review of randomized controlled trials (RCTs) to examine the effectiveness of TwHF and Tripterygium agents, in combination with antihistamines, in chronic urticaria.

\section{Methods}

The review protocol was registered in the PROSPERO database before the start of the review process (CRD42018091595). This study was performed according to the Cochrane Handbook for Systematic Reviews of Interventions [11] and is presented in accordance with the Preferred Reporting Items for Systematic Reviews and
Meta-analyses (PRISMA) guidelines (Additional file 1: Table S1) [12].

\section{Search trials}

We searched databases from their inception dates through February 25, 2018, in order to determine the efficacy and safety of TwHF in chronic urticaria. Included databases were as follows: PubMed, Embase, Cochrane Central Register of Controlled Trials (CENTRAL), China Network Knowledge Infrastructure (CNKI), China Science and Technology Journal Database (VIP), Wan Fang Database, and Chinese Biomedicine (CBM). We combined keywords from $\mathrm{MeSH}$ headings with self-generated key words to identify studies, using unrestricted language. An additional search was performed on relevant websites, including Clinical Trials (http://www.clinicaltrials.gov) and the

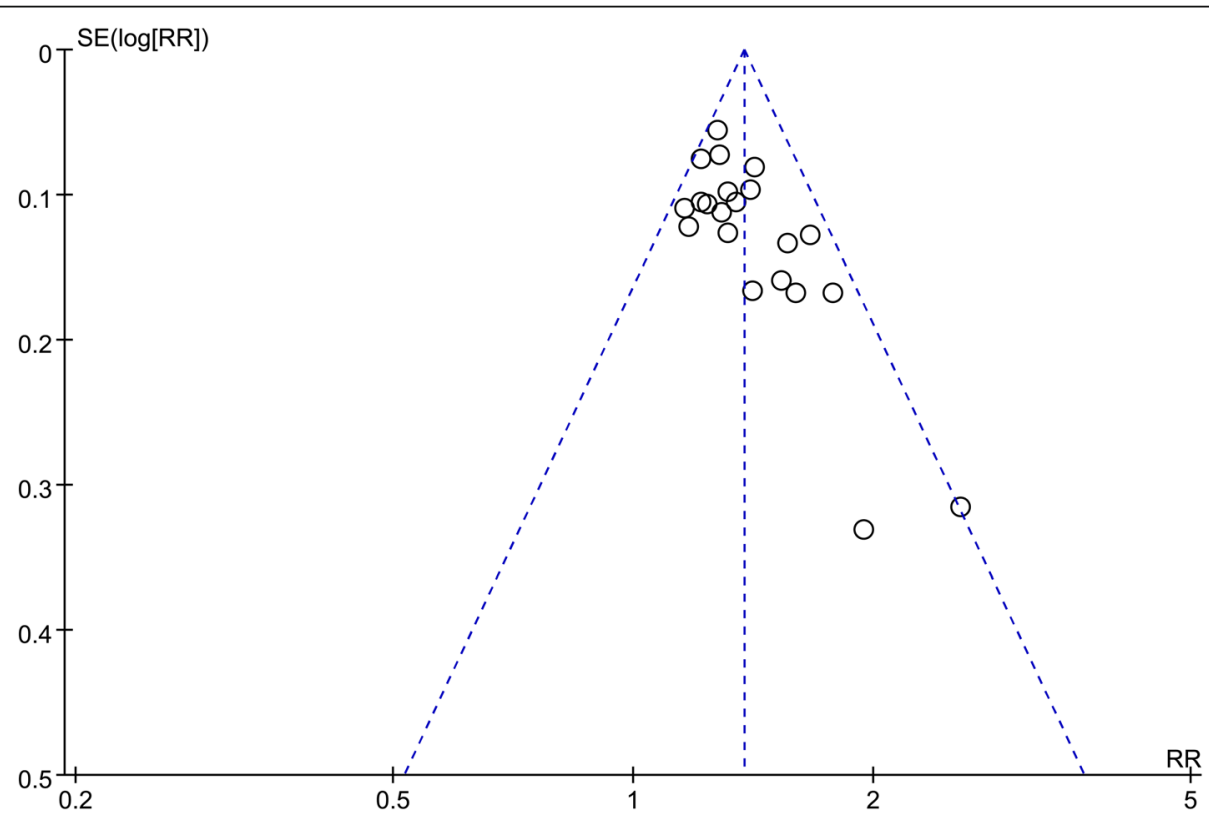

Fig. 3 Funnel plot graph 
Chinese Clinical Trial Registry (http://www.chictr.org.cn/ index.aspx), to identify similar studies.

\section{Inclusion criteria}

RCTs were included if they met the following inclusion criteria: (1) RCTs with explicit diagnostic standards or meeting the criteria for chronic urticaria; (2) RCTs, regardless of race and gender, comprising patients ranging from 12 to 73 years of age; (3) RCTs comparing either TwHF or Tripterygium agents with antihistamines.

\section{Outcomes}

Primary outcomes included symptom scores, such as the Level Four Score method (LFS), Urticaria Activity Score (UAS), and Symptom Score Reduce Index (SSRI). Adverse events (ADE) were also included. Secondary outcome measurements included Dermatology Life Quality Index (DLQI) and Recurrence Rate (RER).

\section{Extraction criteria}

Two reviewers (Y.R, Y.Z) independently determined the following information in each study: lead author, publication year, sample size (treatment group, control group), typical course of disease, interventions (treatment group, control group), outcome criteria, and adverse reactions. In case of differing opinions, consensus was reached after a discussion. We excluded urticaria patients with specific etiologies, such as hereditary angioedema. Control groups using any kinds of Tripterygium agents were excluded. If the literature did not provide control group at any point in the analysis, the study was excluded. Additionally, interventions with unclear dosing regimens and partially recorded adverse events were excluded. We used the most recent article in cases of republication.

\section{Risk-of-Bias assessments}

To analyze included RCTs, two reviewers (Q.Z, Y.L) assessed the Risk-of-Bias independently, using The

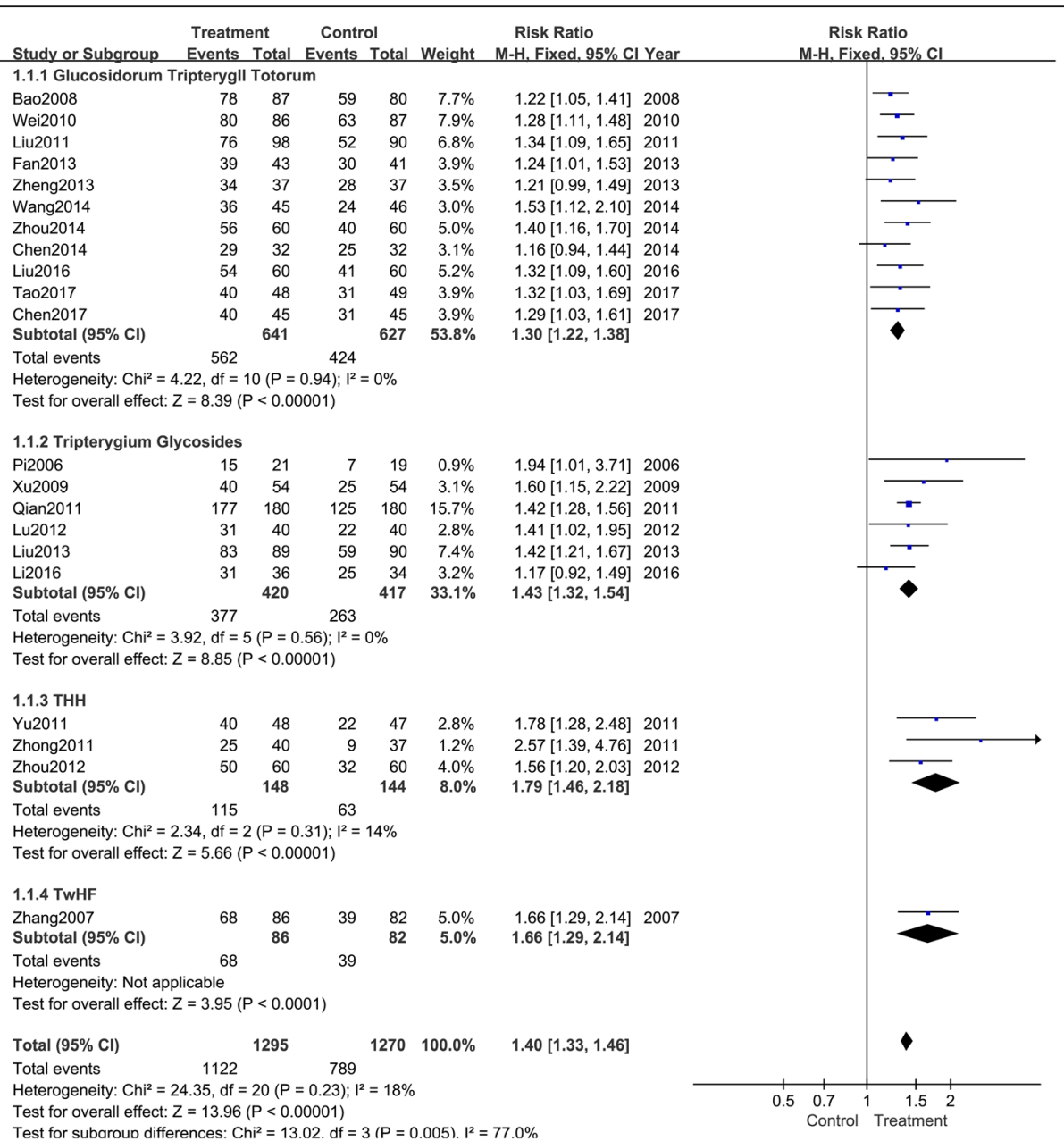

Fig. 4 Meta-analysis of the effectiveness rate of Tripterygium preparations combined with antihistamines versus antihistamines. $\mathrm{Cl}$ indicates confidence interval 
Table 2 Adverse events of included trials

\begin{tabular}{|c|c|c|}
\hline \multirow{2}{*}{$\begin{array}{l}\text { Study } \\
\text { (author/year) }\end{array}$} & \multicolumn{2}{|l|}{ Adverse events } \\
\hline & Intervention & Control \\
\hline Pi 2006 [13] & Two menstrual disorders & Five drowsiness \\
\hline Zhang 2007 [14] & $\begin{array}{l}\text { Eight drowsiness, sleepiness and fatigue, } \\
\text { gastrointestinal disorder, menstrual disorders }\end{array}$ & Five drowsiness, dry mouth, dizzy \\
\hline Bao 2008 [15] & $\begin{array}{l}\text { Seven drowsiness, sleepiness and fatigue, dry mouth; } \\
\text { two gastrointestinal disorder, menstrual disorders }\end{array}$ & Five drowsiness, sleepiness and fatigue, dry mouth \\
\hline Xu 2009 [16] & $\begin{array}{l}\text { Five drowsiness, sleepiness and fatigue, dry mouth; } \\
\text { one irregular menses, abnormal liver function }\end{array}$ & Four drowsiness, dizzy; two gastrointestinal disorder \\
\hline Wei 2010 [17] & $\begin{array}{l}\text { Three drowsiness, sleepiness and fatigue, dry mouth; } \\
\text { two gastrointestinal disorder; one headache, dizzy; } \\
\text { one menstrual disorders, abnormal liver function }\end{array}$ & $\begin{array}{l}\text { Three drowsiness, sleepiness and fatigue, dry mouth; } \\
\text { two gastrointestinal disorder; two headaches, dizzy; }\end{array}$ \\
\hline Zhong 2011 [18] & $\begin{array}{l}\text { Four cases including drowsiness, sleepiness and fatigue, } \\
\text { gastrointestinal disorder }\end{array}$ & $\begin{array}{l}\text { Five cases including drowsiness, sleepiness and fatigue, } \\
\text { gastrointestinal disorder }\end{array}$ \\
\hline Liu 2011 [19] & $\begin{array}{l}\text { Two drowsiness; one sleepiness and fatigue; three } \\
\text { gastrointestinal disorder; one bloating; two menstrual } \\
\text { disorders }\end{array}$ & Two drowsiness; two dry mouth; one dizzy; \\
\hline Qian 2011 [9] & $\begin{array}{l}\text { Four gastrointestinal disorder; three dizzy; three } \\
\text { insomnias; three palpitation; three alopecia }\end{array}$ & Seven drowsiness; one dizzy; one general malaise \\
\hline Yu 2011 [20] & One gastrointestinal disorder; one dizzy & Two headaches, gastrointestinal disorder \\
\hline Lu 2012 [21] & $\begin{array}{l}\text { Two drowsiness; one sleepiness and fatigue; two } \\
\text { gastrointestinal disorder; one dry mouth }\end{array}$ & $\begin{array}{l}\text { One drowsiness; one sleepiness and fatigue; } \\
\text { two dry mouth }\end{array}$ \\
\hline Zhou 2012 [22] & $\begin{array}{l}10 \text { gastrointestinal disorder; three abnormal liver } \\
\text { functions }\end{array}$ & No significant side effects. \\
\hline Fan 2013 [23] & Two drowsiness; three sleepiness and fatigue; two dizzy & Two drowsiness; two sleepiness and fatigue; two dizzy \\
\hline Liu 2013 [24] & Nine drowsiness; two dry mouth & 11 drowsiness; three dry mouth \\
\hline Zheng 2013 [25] & $\begin{array}{l}\text { One drowsiness; one sleepiness and fatigue; one } \\
\text { gastrointestinal disorder; one headache }\end{array}$ & One dizzy; one gastrointestinal disorder; one dry mouth \\
\hline Chen 2014 [26] & $\begin{array}{l}\text { Two drowsiness, sleepiness and fatigue; four } \\
\text { gastrointestinal disorder; }\end{array}$ & Four drowsiness, sleepiness and fatigue; \\
\hline Wang 2014 [27] & $\begin{array}{l}\text { One drowsiness; one sleepiness and fatigue; one } \\
\text { gastrointestinal disorder }\end{array}$ & $\begin{array}{l}\text { One drowsiness; one sleepiness and fatigue; two } \\
\text { gastrointestinal disorder }\end{array}$ \\
\hline Zhou 2014 [28] & $\begin{array}{l}\text { Two drowsiness, sleepiness and fatigue, dry mouth; one } \\
\text { gastrointestinal disorder; one headache, dizzy; one } \\
\text { abnormal liver function }\end{array}$ & $\begin{array}{l}\text { Two drowsiness, sleepiness and fatigue, dry mouth; one } \\
\text { gastrointestinal disorder; one headache, dizzy; }\end{array}$ \\
\hline Li 2016 [29] & One dizzy & Three drowsiness; one sleepiness and fatigue; one dizzy \\
\hline Liu 2016 [30] & $\begin{array}{l}\text { Three drowsiness; two gastrointestinal disorder; } \\
\text { two dizzy }\end{array}$ & $\begin{array}{l}\text { One drowsiness; two gastrointestinal disorder; } \\
\text { one dizzy }\end{array}$ \\
\hline Chen 2017 [31] & One headache, dizzy; one gastrointestinal disorder & $\begin{array}{l}\text { One drowsiness; two headaches, dizzy; one } \\
\text { gastrointestinal disorder }\end{array}$ \\
\hline Tao 2017 [32] & $\begin{array}{l}\text { Three drowsiness, sleepiness and fatigue; five } \\
\text { gastrointestinal disorder; }\end{array}$ & Five drowsiness, sleepiness and fatigue; \\
\hline
\end{tabular}

Cochrane Risk of Bias Tool [11]. Each term was divided into three grades-low risk, high risk, and unclear riskbased on the following criteria: (1) Random sequence generation; (2) Allocation concealment; (3) Blinding of participants and personnel; (4) Blinding of outcome assessment; (5) Incomplete outcome data; (6) Selective reporting; (7) Other bias. Disagreements were discussed between the two reviewers, and if were unresolved, a third reviewer (X.L) was added to the discussion until a consensus was reached.

\section{Statistical analysis}

Revman5.3 software, provided by the Cochrane Collaboration, was utilized to assess dichotomous data, using risk ratio (RR), and continuous data, using mean difference (MD) and standard mean difference (SMD), with 95\% confidence intervals. Heterogeneity was tested using $\mathrm{I}^{2}$ statistics. If there was homogeneity $\left(P>0.1, \mathrm{I}^{2}<50 \%\right)$ in the results, we used a fixed effects model. Otherwise, we used a random effects model. Subgroups analyses were performed to avoid heterogeneity. A funnel plot was used to analyze bias. 


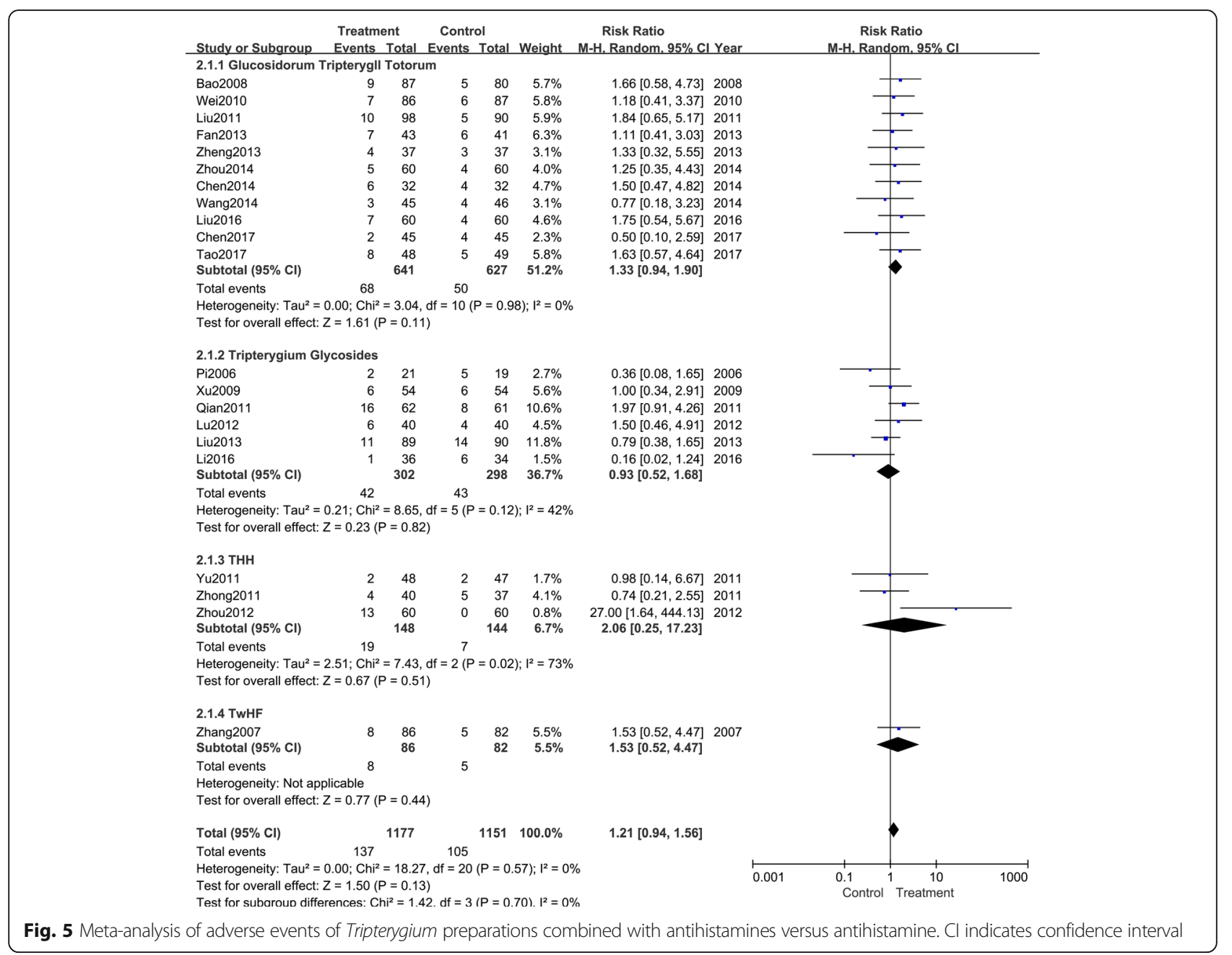

\section{Results}

\section{Included studies and the characteristics}

After initial retrieval from six databases, 186 citations were identified. Sixty duplicate articles were excluded; an additional 126 articles were excluded after reading titles and abstracts. After the full-text reading of the resulting 82 articles, 21 studies [9, 13-32] met our inclusion criteria (Fig. 1).

Altogether, 2565 participants were included in the 21 studies of this analysis, ranging from 12 to 73 years of age. RCTs were published in English and Chinese; all originated from China. All trials utilized diagnostic criteria. Twelve trials $[14,16,19-22,25,27,29-32]$ were in accordance with dermatology monographs in China. One trial [23] applied guidance for the diagnosis and treatment of urticaria (2007). Four trials [9, 13, 17, 24] mentioned diagnostic criteria, while the remaining four trials $[15,18,26,28]$ met diagnostic criteria for urticaria.

The included trials were neither multicentered nor reported syndrome differentiation as illustrated in traditional Chinese Medicine. The basic characteristics of involved studies are presented in Table 1 . In treatment groups, 11 trials $[15,17,19,23,25-28,30-32]$ used GTT, six trials $[9,13,16,21,22,29]$ used TG, three trials $[18,20,22]$ used $\mathrm{THH}$, and one trial [14] used TwHF. The control groups used different types of second-generation antihistamines. Three of these trials $[9,13,22]$ used a combination with mizolastine, five trials $[9,14,18,19,24]$ with cetirizine, nine trials $[15-17$, $25,27,28,30-32]$ used desloratadine, while one trial [9] utilized loratadine. Two trials [23, 29] used ebastine, one trial [20] used terfenadine, and two trials $[21,26]$ used fexofenadine. Duration of treatment ranged from 4 to 12 weeks, and the courses of 19 trials $[9,14-21,23-32]$ were $28 \mathrm{~d}$.

Regarding outcomes, thirteen studies [13-17, 19, 21, $23-25,28,30,32]$ used LFS and SSRI to describe findings, while two trials $[9,22]$ used UAS and SSRI. One trial [18] measured LFS and Total Efficacy Rate (TER) and another [26] only evaluated UAS. The results of four trials $[20,27,29,31]$ were described by symptom assessments. 


\section{Risk of bias}

Ten of the included trials $[16-19,22,24-26,28,32]$ reported random sequence generation, five of which $[16$, $17,19,22,24]$ were based on treatment order and the remaining five $[18,25,26,28,32]$ were based on tables of random numbers. Only one article [18] mentioned allocation concealment, blinding method, whereas the others did not. Patients in three trials $[13,17,18]$ withdrew from the studies and one trial [18] reported intentional (ITT) analysis, while the remaining did not. Three trials $[9,25,32]$ reported complete outcomes. None of the trials reported other bias (Fig. 2). Asymmetric distribution of the trials is presented in a funnel plot (Fig. 3), which implies low-quality methodology and suggests that a publication bias may exist. The small sample size may be a major reason for this possible bias.

\section{Primary outcomes}

\section{Efficacy evaluation}

Effectiveness rate was all evaluated in interventions and controls in 21 trials. According to the variety of Tripterygium agents, all trails were divided into four groups to perform subgroup analyses (Fig. 4). The pooled results indicated that antihistamines combined with GTT (RR: $1.30 ; 95 \%$ CI: $1.22-1.38 ; P<0.001$; fixed model; $\mathrm{I}^{2}=0 \%$; eleven trials), TG (RR: 1.43 ; $95 \%$ CI: $1.32-$ 1.54; $\mathrm{P}<0.001$; fixed model; $\mathrm{I}^{2}=0 \%$; six trials), $\mathrm{THH}$ (RR: $1.79 ; 95 \%$ CI: $1.46-2.18 ; P<0.001$; fixed model; $\mathrm{I}^{2}=14 \%$; three trials), and TwHF (RR: 1.66 ; 95\% CI: $1.29-2.14 ; P<0.001$; fixed model; one trial) were superior to antihistamines alone.

\section{Adverse events}

Each trial reported adverse events (Table 2). Subgroup analysis was performed according to different diversities of Tripterygium agents and different symptoms. As presented in Fig. 5, interventions with GTT (RR: 1.33; 95\% CI: $0.94-1.89 ; P=0.11$; random model; $\mathrm{I}^{2}=0 \%$; eleven trials), TG (RR: 0.93; 95\% CI: 0.52-1.68; $p=0.82$; random model; $\mathrm{I}^{2}=42 \%$; six trials), THH (RR: 2.06 ; 95\% CI: $0.25-$ 17.23; $P=0.51$; random model; $\mathrm{I}^{2}=73 \%$; three trials), and TwHF (RR: 1.53; 95\% CI: 0.52-4.47; $P<0.001$; random model; one trial) were similar to control groups. All the trails reported adverse events including drowsiness, gastrointestinal disorder, menstrual disorders, abnormal liver function, etc. Details are shown in Table 2.

The different symptoms of adverse events are shown in Fig. 6. Zhong et al. [18] reported nine adverse events in two groups; the most common was gastrointestinal disorder. Subgroup analysis revealed that gastrointestinal disorder [9, 14-17, 19-21, 25-28, 30-32] occurred in 47 participants. The pooled results showed that a higher number of adverse events occurred in drug combination groups than in control groups (RR: 2.91 ; 95\% CI: $1.70-$

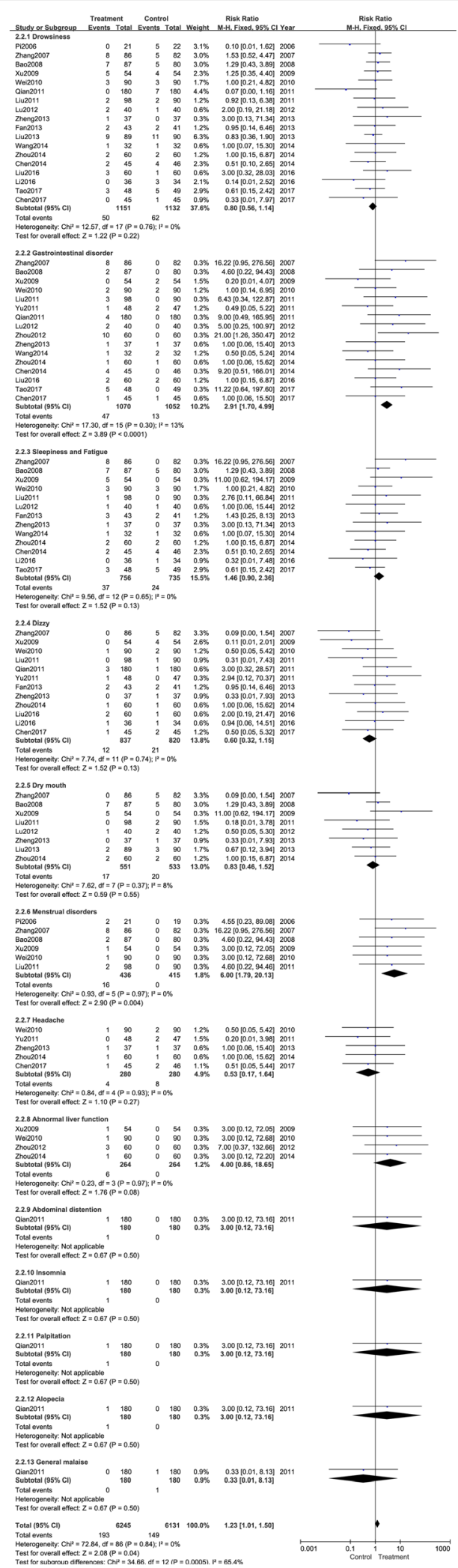

Fig. 6 Meta-analysis of different symptoms of adverse events of Tripterygium preparations combined with antihistamines versus antihistamine. $\mathrm{Cl}$ indicates confidence interval 
4.99; $P<0.001$; fixed model; $\mathrm{I}^{2}=13 \%$; sixteen trials). Six trials $[13-17,19]$ had 16 patients with irregular menses. Subgroup analyses showed that there was a significant difference between the two groups $(p=0.004)$. After treatment with TwHF or any other Tripterygium agents plus antihistamines, the risk of irregular menses was improved for women, whereas control groups did not exhibit this adverse event (RR: 6.00; 95\% CI: 1.79-20.13; $P=0.004$; fixed model; $\mathrm{I}^{2}=0 \%$ ).

In addition to the above two types of adverse events, the most common adverse event was drowsiness, observed in 18 trials [9, 13-17, 19, 21, 23-32] with 50 patients (RR: 0.80 ; 95\% CI: $0.56-1.14 ; P=0.22$; fixed model; $\mathrm{I}^{2}=0 \%$; eighteen trials). Thirty-seven patients experienced sleepiness and fatigue $[14-17,19,21,23,25-$ 29, 32] (RR: $1.46 ; 95 \%$ CI: $0.90-2.36 ; P=0.13$; fixed model; $\mathrm{I}^{2}=0 \%$; thirteen trials). Moreover, 12 participants in 12 trials $[9,14,16,17,19,20,25-32]$ (RR: 0.60; 95\% CI: 0.32-1.15; $P=0.13$; fixed model; $\mathrm{I}^{2}=0 \%$ ) experienced dizziness. Eight trials $[14-17,19,21,22,25,28]$ (RR: 0.83; 95\% CI: 0.46-1.52; $P=0.55$; fixed model; $\mathrm{I}^{2}=8 \%$ ) reported dry mouth. Five trials [17, 20, 25, 28, 31] (RR: 0.53; 95\% CI: 0.17-1.64; $P=0.27$; fixed model; $\left.\mathrm{I}^{2}=0 \%\right)$ reported headache. Four trials [16, 17, 22, 28] reported abnormal liver function (RR: 4.00; 95\% CI: 0.86-18.65; $P=0.08$; fixed model; $\mathrm{I}^{2}=0 \%$. Qian et al. [9] reported abdominal distention (RR: 3.00; 95\% CI: $0.12-$ 73.16; $P=0.50$; fixed model), palpitation (RR: 3.00; 95\% CI: $0.12-73.16 ; P=0.50$; fixed model), alopecia (RR: $3.00 ; 95 \%$ CI: $0.12-73.16 ; P=0.50$; fixed model), and insomnia (RR: 3.00 ; 95\% CI: $0.12-73.16 ; P=0.50$; fixed model) when treated with Tripterygium agents.

\section{Secondary outcomes}

\section{Dermatology life quality index (DLQI)}

DLQI is an important content in urticaria evaluation; five trials $[9,17,25,30,32]$ have described it. One study [25] measured quality of sleep and daily activity in the place of DLQI. Two studies [9, 32] reported scores, while the remaining $[17,30]$ reported affected cases. As shown in Fig. 7, DLQI (RR: 1.23 ; 95\% CI: $1.09-$ 1.40; $P=0.001$; fixed model; $\mathrm{I}^{2}=0 \%$; two trials) was obviously improved in the intervention groups.

\section{Quality of sleep}

Three trials $[17,25,32]$ measured quality of sleep as an outcome. One study [32] showed that the scores in the drug combination group were lower than in controls, which indicates better sleep intervention. Meta-analysis showed that in the other two studies, Tripterygium agents combined with antihistamines were significantly better than antihistamines alone (RR: 1.50; 95\% CI: 1.07-2.12; $P=0.02$; random model; $\mathrm{I}^{2}=62 \%$; two trials) (Fig. 8).

\section{Quality of daily activity}

Three trials $[17,25,32]$ used quality of daily activity as an evaluation method. One study [32] showed that compared with antihistamine alone, daily activity in the drug combination group was of a higher quality. Results of the remaining trials showed obvious improvements in the treatment groups, when compared with control groups (Fig. 9) (RR: 1.49; 95\% CI: 1.25-1.78; $P<0.001$; fixed model; $\mathrm{I}^{2}=16 \%$; two trials).

\section{Recurrence rate}

Six trials $[9,16,24,25,28,32]$ utilized recurrence rate as a secondary outcome. Subgroup analysis showed that patients treated with Tripterygium agents had lower recurrence rates, that did patients without the treatment (RR: 0.34; 95\% CI: 0.25-0.45; $P<0.001$; fixed model; $\mathrm{I}^{2}=43 \%$; six trials) (Fig. 10).

\section{Discussion}

This systematic review, including 21 trials, evaluated the efficacy and safety of Tripterygium in the treatment of chronic urticaria. Although the quality of these studies were not highly satisfactory, the results showed that, compared to treatment with antihistamines alone, the combination with TwHF or Tripterygium agents improved both, the symptoms and quality of life; even the recurrence rates were lower. However, adverse events could not be ignored. There was marked difference between the two groups in terms of gastrointestinal reactions and menstrual disorders. A total of 47 participants in the drug combination groups experienced gastrointestinal discomfort. Sixteen female patients in these groups experienced menstrual disorders, while those in control

\begin{tabular}{|c|c|c|c|c|c|c|c|c|c|c|c|}
\hline & \multirow{2}{*}{$\begin{array}{l}\text { Study or Subgroup } \\
\text { Wei2010 }\end{array}$} & \multicolumn{2}{|c|}{ Tripterygium } & \multicolumn{2}{|c|}{ Control } & Weight & $\begin{array}{l}\text { Risk Ratio } \\
\text { M-H. Fixed. } 95 \% \text { Cl Year }\end{array}$ & \multicolumn{3}{|c|}{ Risk Ratio } & \\
\hline & & 71 & 86 & 59 & 87 & $57.7 \%$ & $1.22[1.02,1.45] 2010$ & & & & \\
\hline & Liu2016 & 54 & 60 & 43 & 60 & $42.3 \%$ & $1.26[1.05,1.50] 2016$ & & & $=$ & \\
\hline & Total $(95 \% \mathrm{Cl})$ & & 146 & & 147 & $100.0 \%$ & $1.23[1.09,1.40]$ & & & & \\
\hline & Total events & 125 & & 102 & & & & & & & \\
\hline & $\begin{array}{l}\text { Heterogeneity: } \mathrm{Chi}^{2}= \\
\text { Test for overall effect: }\end{array}$ & $\begin{array}{l}0.06, d f=1 \\
Z=3.26(P\end{array}$ & $\begin{array}{l}(P=0.8 \\
=0.001\end{array}$ & $\begin{array}{l}\text { 81); }\left.\right|^{2}=0 \\
\text { 1) }\end{array}$ & & & & 0.5 & $0.7{ }_{\text {Control }}^{1}$ & $\begin{array}{lr}1 & 1.5 \\
\text { Treatment }\end{array}$ & 2 \\
\hline
\end{tabular}




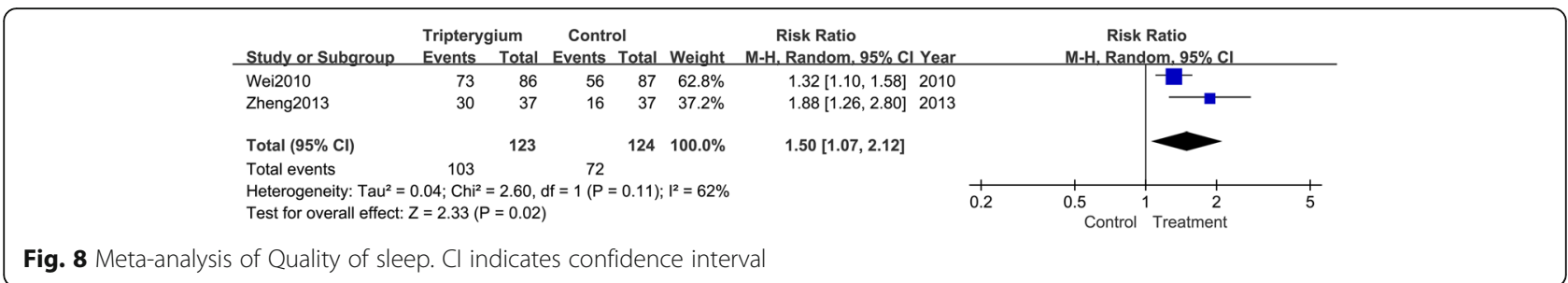

groups did not. For men who had not procreated, one trial [22] evaluated sperm motility in the intervention group and found an influence on sperm motility, which suggests that there may be a certain risk to the reproductive system.

In China, Wen et al. [33] performed a systematic evaluation in 2015 of GTT combined with antihistamines for chronic idiopathic urticaria, including 21 trials. Results of their systematic review were consistent with our findings that combined GTT with antihistamines had an obvious effect. However, as increasing evidence emerges every year, systematic reviews should be updated in a timely fashion. In this review, we added literature published in the most recent two years and formulated a set of rigorous inclusion and exclusion criteria. Furthermore, we have included all types of Tripterygium preparations.

Urticaria is known as a mast cell-driven disease, the key aspect of which is degranulation of mast cells with release of histamines and synthesis of inflammatory cytokines, causing an increase in capillary permeability and leading to edema of the dermis. Although antihistamines are effective, there are reports of drug resistance, high recurrence rates, and several side effects in RCTs. TwHF, as a significant traditional Chinese herbal medicine, has effects on numerous symptoms, according to basic theory of Chinese medicine. Pharmacological studies demonstrated that TwHF plays a significant role in antitumor, anti-inflammatory, and immune suppression mechanisms [34]. Chronic urticaria is classically thought to have a basis in autoimmunity and mast cells are vital to it. It has been reported by Liu et al. [35] and Yao et al. [36] that tripterine, a primary component in TwHF, has the ability to inhibit the degranulation of mast cells and histamine release. Although the role of TwHF in chronic urticaria remains unclear, multiple studies have reported stronger effects when treated with TwHF and its agents.

Nevertheless, adverse events are always a focus of concern. It is generally known that the active ingredients in TwHF are also toxic components that may be harmful to the liver, kidneys, reproductive tissues, and immune tissues. Although Tripterygium agents are developed with attenuation measures, toxic effects are inevitable. In this meta-analysis, we found that patients in drug combination groups were more likely to experience gastrointestinal disorders and altered menstruation. Gastrointestinal disorder is a serious adverse event in trials involving TwHF and Tripterygium agents, the incidence rate of which is $25.2 \%$ [37]. Even within the normal dose range, the main manifestations are nausea, vomiting, and bloating. Yang et al. [38] treated NIH mice and Sprague-Dawley rats with different doses and found that they all exhibited pathological changes in the gastrointestinal tract in a dose-dependent manner. Over time, gastrointestinal reactions are gradually adapted to. These may be ascribed to spasms of smooth muscle caused by Tripterygium agent-based irritation of the gastrointestinal mucosa [39]. However, this kind of adverse event was tolerable; after continuing medication or drug withdrawal, it disappeared spontaneously. It has been reported that impairment of the reproductive system is the second most common adverse event, with an incidence rate of $16.7 \%$ [37]. During treatment, 16 female patients suffered menstrual disorder, which may result from dysfunction of hypothalamic-hypophyseal-ovarian axis [40]. TwHF and Tripterygium agents have abilities to inhibit

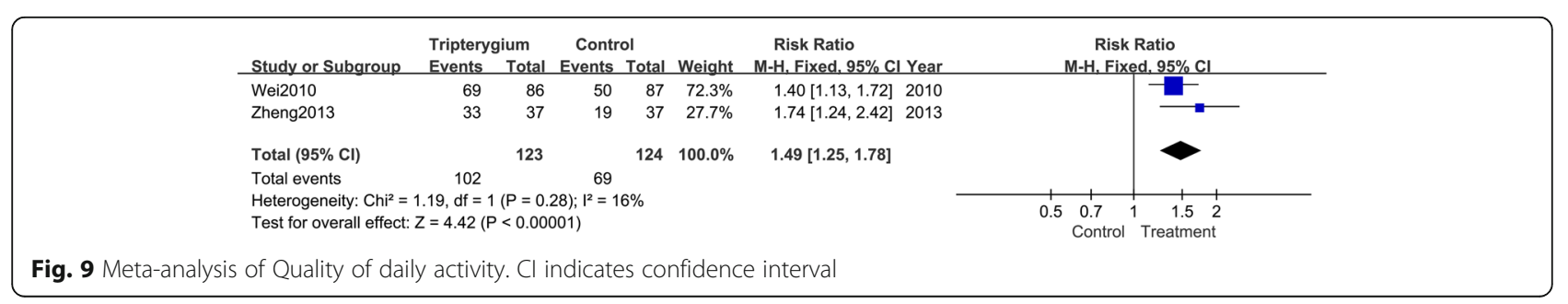




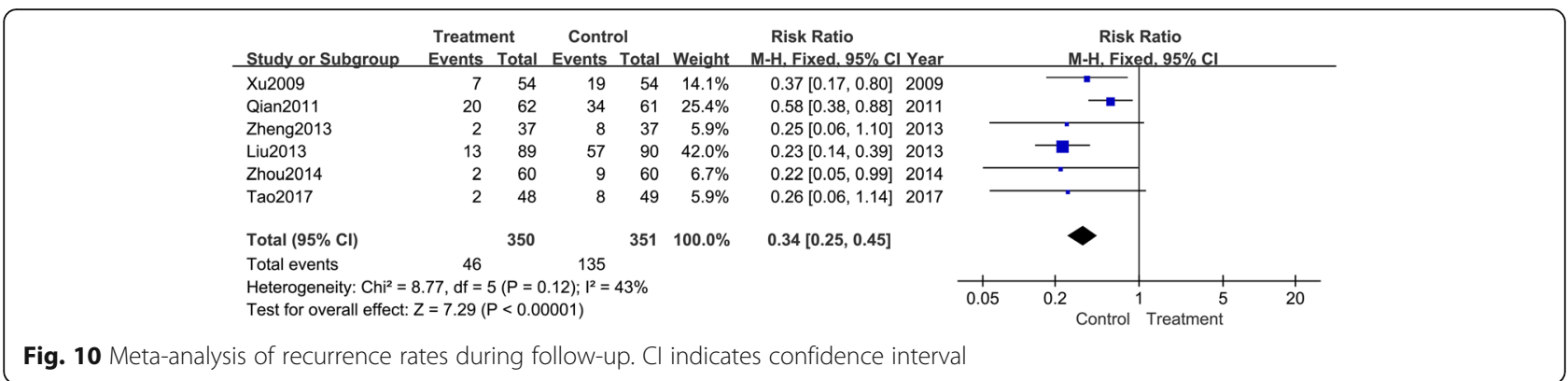

formation of the corpus luteum and follicles, suppress luteal function and ovulation, and to decrease the levels of estrogen and progesterone; consequently, they may reduce ovarian function [41]. For males, lowered sperm motility is the most common side effect. After discontinuation of the drug, damage to the reproductive system can be restored.

In addition, some included trials reported abnormal liver function after administration of TwHF or Tripterygium agents. Although these results were not statistically significant, damage to liver function cannot be ignored. Three trials reported two patients with elevated transaminases, whereas three patients showed slightly abnormal liver function. Lipid production and peroxidation in the liver, induced by TwHF, may be related to this type of adverse event [42].

Currently, numerous methods of alleviating toxic effects have been suggested, such as compatibility with medicines, use of low-dose medication over the long term, and stronger prevention measures [43, 44]. Once adverse events appear, patients should discontinue medication immediately, and clinicians should perform measures to manage adverse events when necessary.

There are also some limitations of this systematic review: (1) the quality of the included trials was not very high. Of the 21 trials, five were RCTs and another five were quasi-randomized controls; the remaining trials simply mentioned "random." As for allocation concealment and blinding method, only one study described these aspects in detail. Thus, there appeared to be a high risk of selection and detection bias; (2) the sample size was insufficient to reach a robust conclusion; (3) the very low number of events (several subgroup analysis was included in only one study in Figs. 4, 5 and 6) on which the results were based was another limitation that can affect the interpretation of results; (4) the funnel plot was asymmetrical, suggesting a risk of publication bias.

\section{Conclusion}

To summarize, the combination of TwHF or Tripterygium agents with antihistamines may be effective for chronic urticaria. However, adverse events should always be noted. The compatibility of medicines, use of low-dose medication over the long term, and the strength of preventive approaches are appropriate methods to reduce toxicity. Furthermore, the study of this treatment requires large sample, multi-center design, and high-quality clinical trials to ascertain its usage in the broader medical field.

\section{Additional file}

Additional file 1: Table S1. PRISMA checklist. (DOC 69 kb)

\section{Abbreviations}

ADE: Adverse Events; Cl: confidence interval; DLQI: Dermatology Life Quality Index; GTT: Glucosidorum Tripterygll Totorum; LFS: Four-level Score Method; MD: Mean Difference; RER: Recurrence Rate; RR: Risk Ratio; SA: Symptom Assessment; SMD: Standard Mean Difference; SSRI: Symptom Score Reduce Index; TER: Total Effective Rate; TG: Tripterygium Glycosides;

THH: Tripterygium hypoglaucum (levl.) Hutch; TwHF: Tripterygium wilfordii Hook F; UAS: Urticaria Activity Score; VAS: Visual Analogue Scales

\section{Acknowledgements}

Thanks are due to Dr. Ting D for suggestions regarding this study.

\section{Funding}

This project was supported by the Shanghai Rising-Star program (no. 16QA1403800). It was also supported by a grant from the Development Fund for Shanghai Talents (no. 2017047), Young Talent Supporting Program of China Association of Traditional Chinese Medicine (QNRC2-B05), the NSFC of China (no. 81874470, 81473682), and Shanghai Shen Kang Hospital Development Center Project (no. 16CR2035B).

\section{Availability of data and materials}

All data generated during this study are included in this article and its supplementary information files.

\section{Authors' contributions}

$\mathrm{XL}$ and $\mathrm{BL}$ conceived this study. $\mathrm{LL}$ and $\mathrm{H}-\mathrm{BZ}$ designed this study. $\mathrm{H}-\mathrm{BZ}$ performed literature researches. YR, YZ extracted data, $X L Q Z$ and $Y L$ assessed the quality of trails. $L L, H-B Z, X-Y S, X C$ and $X L$ analyzed the data. $\mathrm{LL}$ and $\mathrm{H}-\mathrm{BZ}$ prepared the original draft. $\mathrm{LL}, \mathrm{H}-\mathrm{BZ}, \mathrm{XL}, \mathrm{BL}, \mathrm{BZ}$ and $\mathrm{C}-\mathrm{QY}$ contributed to the revision of the manuscript. All authors have read and approved the final manuscript.

Ethics approval and consent to participate

This study was based on previously published studies, therefore, ethical approval and patient consent are not relevant.

Consent for publication

Not applicable. 


\section{Competing interests}

The authors declare that they have no competing interests.

\section{Publisher's Note}

Springer Nature remains neutral with regard to jurisdictional claims in published maps and institutional affiliations.

\section{Author details}

'Department of Dermatology, Yueyang Hospital of Integrated Traditional Chinese and Western Medicine, Shanghai University of Traditional Chinese Medicine, Shanghai 200437, China. ${ }^{2}$ Institute of Dermatology, Shanghai Academy of Traditional Chinese Medicine, Shanghai 201203, China. ${ }^{3}$ Department of Dermatology, Shaanxi Hospital of Traditional Chinese Medicine, Xi'an 710003, China. ${ }^{4}$ Department of Pharmacology \& Experimental Therapeutics, Boston University School of Medicine, Boston, MA 02118, USA

\section{Received: 26 May 2018 Accepted: 1 August 2018}

\section{Published online: 31 August 2018}

\section{References}

1. Zuberbier T, Aberer W, Asero R, Bindslev-Jensen C, Brzoza Z, Canonica GW, et al. The EAACI/GA2LEN/EDF/WAO guideline for the definition, classification, diagnosis, and management of urticaria: the 2013 revision and update. Allergy. 2014:69:868-87.

2. Powell RJ, Du Toit GL, Siddique N, Leech SC, Dixon TA, Clark AT, et al. BSACl guidelines for the management of chronic urticaria and angio-oedema. Clin Exp Allergy. 2007;37:631-50.

3. Kaplan AP, Greaves M. Pathogenesis of chronic urticaria. Clin Exp Allergy. 2009;39:777-87.

4. Law SK, Simmons MP, Techen N, Khan IA, He MF, Shaw PC, et al. Molecular analyses of the Chinese herb Leigongteng (Tripterygium wilfordii Hook.F.). Phytochemistry. 2011;72(1):21-6.

5. Corson TW, Crews CM. Molecular understanding and modern application of traditional medicines: triumphs and trials. Cell. 2007;130:769-74.

6. Liao ZH, Zhou ZH, Dai GD. Clinical effect of methotrexate and Leigong Teng duo Dai Pian on treatment of rheumatoid arthritis. Chin J Biochem Pharm. 2016:36:136-8.

7. Wu WH, Wang H, Zhang MP, Huang SM. Effects of Tripterygium on diabetic nephropathy: a systematic review. Chin J Evid-based Med. 2010:10:693-9.

8. Liu W, Yan L, Zhu Q, Shao FM. Therapeutic effect of Tripterygium glycosides plus prednisone on moderate active systemic lupus erythematosus. J Chin Pract Diagn Ther. 2014;28:1234-8.

9. Qian M, Zhang SY. Clinical efficacy of Triptergium Wilfordii combined with antihistamines on treating chronic Urticaria. Chin J Dermato Venerol Integ Trad W. 2011;10:359-62.

10. Meng $L Y$, Zhang $C M$, Yang $A B, Y u Z H$. The clinical efficacy of Tripterygium hypoglaucum (levl.) hutch in combination with $5 \%$ doxepin cream on chronic urticaria. J. Clin Dermatol. 2006:35:118.

11. Higgins JPT. Green S, eds. Cochrane Handbook for Systematic Reviews of Interventions, version 5.1 .0 (updated March 2011). Cochrane Collaboration website. http://training.cochrane.org/handbook [update March 2011]. Accessed 25 Feb 2018.

12. Liberati A, Altman DG, Tetzlaff J, Mulrow C, Gøtzsche PC, loannidis JP, et al. The PRISMA statement for reporting systematic reviews and meta-analyses of studies that evaluate healthcare interventions: explanation and elaboration. BMJ. 2009;21(339):b2700.

13. Pi XB, Wang XX, Mai YM, Li JH, 40 cases of mizolastine combined with tripterygium glycosides in the treatment of chronic idiopathic urticaria. Southern China Journal of Dermato-Venereol. 2006:13:130-2.

14. Zhang L, Xiong B, Zhang QY. Observation on efficacy of levocetirizine combined with Tripterygium in chronic urticaria. China J Lepr Skin Dis. 2007:23:1031-2.

15. Bao LX. Observation on efficacy of desloratadine combined with Glucosidorum Tripterygll Totorum in chronic urticaria. China J Lepr Skin Dis. 2008:24:568-9.

16. Xu YM. Observation on efficacy of desloratadine combined with tripterygium glycosides in chronic urticaria. Chin J Dermato Venerol Integ Trad W Med. 2009:8:171-2

17. Wei YH, Zhang JH, An RZ, Wang J-I. Combination effect of Tripterygium Wilfordii with Desloratadine on theTreatment of chronic idiopathic Urticaria. Chin J Derm Venereol. 2010;24:1170-2.
18. Zhong JQ, Xian DH, Xu Y, Liu J. Efficacy of Tripterygium hypoglaucum hutch in adults with chronic Urticaria. J Altern Complement Med. 2011;17:459-64.

19. Liu J. Observation on efficacy of levocetirizine hydrochloride combined with Glucosidorum Tripterygll Totorum in chronic urticaria. Chin J Misdiagnostics. 2011;11:4356.

20. Yu JM, Liang GX, Wang JX, Liao J. The clinical efficacy of tripterygium hypoglaucum hutch tablet combined with terfenadine tablet in patients with chronic urticaria. China Prac Med. 2011;6:20-1.

21. Lu Q. 40 cases of fexofenadine hydrochloride combined with tripterygium glycosides in the treatment of chronic urticaria. Traditional medicine. 2012;21:97-8

22. Zhou JW. The clinical investigation and safety analysis of patients with chronic Urticaria in the treatment of Tripterygii Hypoglauci and mizolastine. North Pharm. 2012:9:10-1.

23. Fan FR. Clinical Observation on Therapeutic Effects of Chronic Urticaria Treated by Ebastine and Tripterygium wilfordii Hook.F. J Med Theor \& Prac. 2013;26:993-4

24. Liu JY, Chen C. Observation on curative effect of cetirizine combined with tripterygium glycosides on chronic urticaria. J Prac Med Techniq. 2013;20:658-9.

25. Zheng WZ, Pu R, Chen ZC, Shi JM. Observation on curative effect of desloratadine combined with Glucosidorum Tripterygll Totorum in chronic idiopathic urticaria. Contemp Med. 2013;19:74-5.

26. Chen HJ. Effect observation of fexofenadine combined with Tripterygium glycosides in treating chronic urticaria. Chongqing Med. 2014;43:3302-4

27. Wang Q. Observation on desloratadine combined with Glucosidorum Tripterygll Totorum in chronic idiopathic urticaria. Chin J Modern Drug Appl. 2014;8:98-9.

28. Zhou ZD. Clinical curative effect of desloratadine combined with Glucosidorum Tripterygll Totorum in chronic idiopathic urticaria. Med Inf. 2014;27:304-5.

29. Li WH. Curative effect of ebastine combined with tripterygium glycosides in the treatment of chronic urticaria. Shenzhen J Integrated Traditional Chin and Western Med. 2016:26:88-90.

30. Liu Z. Clinical curative effect of desloratadine combined with tripterygium glycosides on chronic idiopathic urticaria. Clini Med. 2016;36:21-2

31. Chen T. Curative effect of desloratadine combined with Glucosidorum Tripterygll Totorum in chronic idiopathic urticaria. Chinese And Foreign Med Res. 2017;15:24-6

32. Tao YF. Clinical curative effect of desloratadine combined with Glucosidorum Tripterygll Totorum in chronic urticaria. Modern Prac Med. 2017;29:1345-6.

33. Wen WT, Huang JJ, Wang PL, Yu S. System evaluation of Glucoside Tripterygium Total combined with antihistamine medicine for chronic idiopathic Urticaria. Chin J Inform on TCM. 2016;23:46-50.

34. Li XJY, Jiang ZZ, Zhang LY. Triptolide: progress on research in pharmacodynamics and toxicology. J Ethnopharmacol. 2014;155:67-79.

35. Liu RL, Liu ZL, Li O, Oiu ZM, Lv HJ, Yang ZM, Hong GZ. The experimental study on the inhibitory effect of tripterine on airway inflammation in asthmatic mice. Chin J Tuberc Respir Dis. 2004:27:165-8.

36. Yao CY, Wang T, Jiang YL, Zheng X, Lin PH. Effect of celastrol on degranulation of mast cell and possible mechanism of PI3KJAKT/GSK3- $\beta$ pathway. Fujian Med J. 2017;39:61-4

37. Li YL, Qi XY. Literature investigation and analysis of adverse events in 294 cases of Tripterygium. Shanxi Med J. 2011;40:88-90.

38. Yang W, Huang YK, Lei LX, Xiao BQ, Sun H. Study on toxicity of Tripterygium glycosides to digestive tract. The seventh National Toxicology Conference of the Chinese Society of Toxicology and the eighth Hubei science and technology forum; 2015; Wuhan, Hubei. China

39. Fan $X Z$, Chen $Y$, Li XD. Investigation of adverse reactions caused by Tripterygium wifordii Hook.f in patients with immune diseases. Chin J Integrated Traditional and Western Nephrology. 2001;02:83-5.

40. Zhou LZ, Gu JH. Research progress on toxic side effects and detoxification methods of Tripterygium wilfordii to female reproductive system. Gansu J TCM. 2011;24:75-7.

41. Xi YB, Xia BY, Zheng DM. Research status of reproductive toxicity of Tripterygium wilfordii Hook.F. Nei Mongol J Tradit Chin Med. 2011;30:126-8.

42. Cao LJ, Yan M, Li HD, Zhang KB, Fang PF. Progress on mechanism of Tripterygium wilfordii-induced liver injury and detoxification mechanism of icorice. China Journal of Chinese Materia Medica. 2015:40:2537-41.

43. Li WY. Adverse reactions and prevention measures of Tripterygium wilfordi and its preparation. Capital Medicine. 2012;19:47-9.

44. Li HG, Ji W, Su JM, Song YN, Ma CG. Literature research of the hepatotoxicity of Glucoside Tripterygium Total and its synergism and toxicity reducing effects. Chin J Integr Trad West Med. 2012;32:415-8. 